\title{
Declining male births with increasing geographical latitude in Europe
}

\author{
Victor Grech, P Vassallo-Agius, Charles Savona-Ventura
}

\begin{abstract}
Objective-Demographic studies in various industrialised countries have shown a decline in male births in the latter half of the 20th century from the expected ratio of 0.515 (males/total). This study analyses trends in this ratio over the period 1890 to 1995 in Malta, and also analyses this ratio for Western European countries for the period 1990-1995.

Design-Births subdivided by sex were obtained from official Maltese publications. European countries were grouped according to geographical latitude by banding countries into three groups: Northern Mediterranean, Central European and Scandinavian. Births by sex for these countries were also analysed for the period 1990-1995.

Results-No decline in the ratio of male births to total births was noted in Malta over the period 1916-1995. However, the ratio was higher than expected $(\mathrm{n}=151766$, ratio $=0.517(95 \%$ confidence intervals $(95 \% \mathrm{CI})$ : $0.514,0.519)$. Moreover, during the period 1890-1899 $(n=66874)$, the ratio was $0.523(95 \% \mathrm{CI}$ : $0.519,0.527)$, even higher than observed during the 20th century $\left(\chi^{2}=8.3, p=0.004\right)$. Analysis of European births showed a much higher ratio of male births in the south of Europe than in the north $\left(\chi^{2}=87.2, p<0.0001\right)$.

Conclusions-The findings were unable to explain the higher incidence of male births in the south of Europe, but it is speculated that ambient temperatures may not only affect fertility, but also influence sex ratios at birth.
\end{abstract}

(F Epidemiol Community Health 2000;54:244-246)

Paediatric

Department, St Luke's

Hospital, Malta

V Grech

Department of

Obstetrics and

Gynaecology, St Luke's

Hospital

C Savona-Ventura

Medical School, University of Malta

P Vassallo-Agius

Correspondence to:

Dr Grech, Paediatric

Department, St Luke's

Hospital, Guardamangia

Malta

Accepted for publication 4 September 1999

Recent studies from various countries have shown a decline in male births, with a drop in the ratio of male to female births from the traditional 1.06:1 over the past three to five decades. ${ }^{1-4}$

Malta is a small island in the central Mediterranean with a total area of $246 \mathrm{~km}^{2}$ and a relatively closed population of around 370 000. Registration of births is mandatory, and accurate demographic records have been kept for many decades, making this an ideal location for epidemiological studies.

The aims of this study were to test two null hypothesis: that there has not been a decline in male births in Malta over the period 1890 1995, and that there are no significant differences in the ratio of male births to total births in Europe associated with geographical latitude.

\section{Methods}

MALE/FEMALE RATIO IN MALTA

The ratio of male to female live births $(\mathrm{M} / \mathrm{F})$ is misleadingly and traditionally defined as the number of live male births in a particular year divided by the total births for the same yearthat is, male births are expressed as a fraction of total births - and this definition is used in this paper. Annual births subdivided by gender, were obtained from official Maltese government publications. ${ }^{56}$ These data were not available for the period 1900-1915. Because of the relatively small number of annual births (currently about 4000/annum), analysis was carried out on five year totals for male and female live births, for the period 1890-1995.

M/F BY GEOGRAPHICAL LATITUDE IN EUROPE

Western European countries were broadly grouped into three geographical bands using latitude. The bands included countries on the northern shores of the Mediterranean Sea (latitude $40-45^{\circ}$ ), Central European countries $\left(45-55^{\circ}\right)$, and Scandinavian countries $\left(>55^{\circ}\right)$ (table 1). Male and female live births for these countries for the years 1990-1995 were obtained from the United Nations Demographic Yearbook ${ }^{7}$ for those years when these data were reported.

Stillbirths are not included in this study. The quadratic equations of Fleiss were used to calculate exact $95 \%$ confidence intervals (95\% CI). ${ }^{8}$ The $\chi^{2}$ test for trend was used to analyse changing trends in $\mathrm{M} / \mathrm{F}$. A p value $\leqslant 0.05$ was taken to represent a statistically significant result.

\section{Results}

Annual births ranged between 11612 (1947) and 4613 (1995). The annual $\mathrm{M} / \mathrm{F}$ varied between 0.503 and 0.530 for the period 1916-1995, with an overall M/F of 0.517 (95\% CI: $0.514,0.519)$. No declining trend was

Table 1 European countries banded by latitude

\begin{tabular}{lll}
\hline Latitude & & \\
\hline $40-45^{\circ}$ & $45-55^{\circ}$ & $>55^{\circ}$ \\
\hline Portugal & France & Denmark \\
Italy & Austria & Iceland \\
Greece & Switzerland & Finland \\
Spain & Germany & Sweden \\
and & Poland & \\
Malta & Ireland & \\
& UK & \\
& Netherlands & \\
& & \\
\end{tabular}




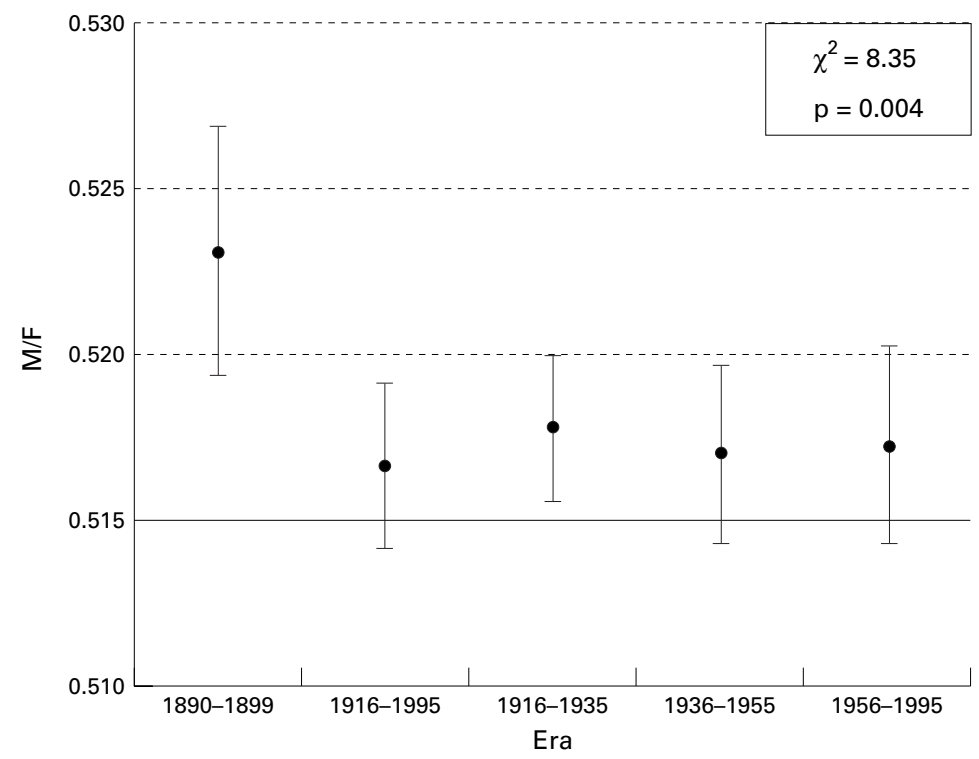

$0.515=$ expected ratio of male births divided by total births. Range shows $95 \%$ confidence intervals for the plotted proportion.

Figure 1 Ratio of male births to total births in Malta for different periods.

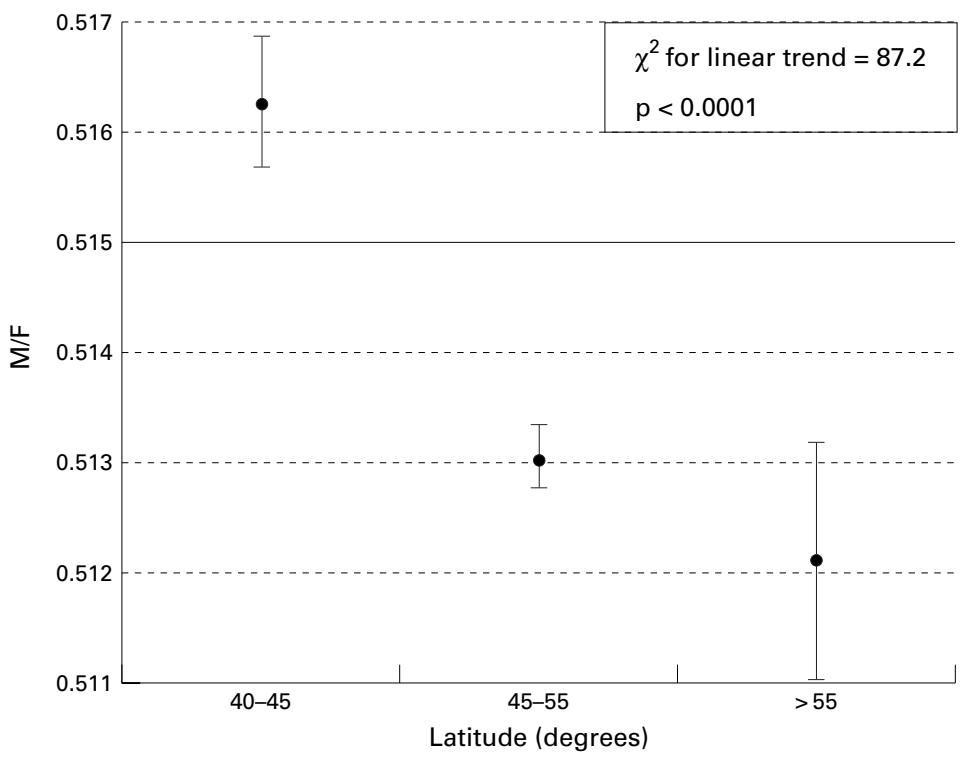

$0.515=$ expected ratio of male births divided by total births. Range shows $95 \%$ confidence intervals for the plotted proportion.

Figure 2 Ratio of male births to total births by geographical latitude for the period 1990-1995.
KEY POINTS

- The universally expected ratio of male live births to total live births is 0.515 .

- Recent studies have shown a decline in this figure, with less male preponderance.

- No such decline is seen in Malta this century, but the figure is considerably and consistently $>0.515$.

- This figure also declines with increasing latitude in Europe over the period 19901995.

- Is this a temperature/climate effect?

was significantly higher than the ratio observed during the 20th century $\left(\chi^{2}=8.3, p=0.004\right)$ (fig 1).

For all of the years available (1890-1899 and 1916-1995), M/F was 0.519 (95\% CI:0.517, $0.521)$, significantly higher than the expected value of 0.515 .

M/F BY GEOGRAPHICAL LATITUDE IN EUROPE A highly significant decline in $\mathrm{M} / \mathrm{F}$ was found for births by increasing latitude $\left(\chi^{2}\right.$ for trend $=80.2, \mathrm{p}<0.0001$ ) (fig 2).

\section{Discussion}

M/F IN MALTA

A decline in male births over varying time frames during the second half of the 20th century has been noted in various developed countries, including Denmark, the Netherlands, Canada and the United States. ${ }^{1-4}$ It is known that the male fetus is more susceptible to environmental insults, ${ }^{4}$ and indeed the male fetus is generally more fragile and prone to be stillborn. ${ }^{9}$ Toxic byproducts of industrialisation causing increased loss of male fetuses has been put forward as a cause for the observed decline in male births. No such trends were present in Malta in the 20th century. However, the $\mathrm{M} / \mathrm{F}$ was consistently greater than the expected value of 0.515 (fig 1), and for this reason, $\mathrm{M} / \mathrm{F}$ was analysed for European countries according to broad geographical regions, based on latitude.

M/F BY GEOGRAPHICAL LATITUDE IN EUROPE

The countries to the south of Europe have a significantly higher number of male births than those towards the north of Europe. This finding has not been previously reported, to the best our knowledge. It is not possible to identify factors that have led to the differences in these sex ratios at birth. An obvious potential factor is that of temperature, and studies relating to sex ratios at birth, and not just to fertility, may help to elucidate the findings of this study. ${ }^{11}$

Funding: none.

Conflicts of interest: none.

1 Moller $\mathrm{H}$. Change in male-female ratio among newborn infants in Denmark. Lancet 1996;348:828-9.

2 Van der Pal-de Bruin KM, Verloove-Vanhorick SP, Roeleveld N. Change in male-female ratio among newborn infants in Netherlands. Lancet 1997;349:62.

3 Allan BB, Brant R, Seidel JE, et al. Declining sex ratios in Canada. Can Med Assoc F 1997;156:37-41. 
4 Davis DL, Gottlieb MB, Stampnitzky JR. Reduced ratio of male to female births in several industrial countries-a sentinel health indicator? $7 A M A$ 1998;279:1018-23.

5 Central Office of Statistics. Demographic review for the Maltese Islands. Malta: Central Office of Statistics, (Annual publications)

6 Department of Health. Health Reports. Malta: Department of Health, (Weekly publications).

7 United Nations. Demographic Yearbook. New York: United Nations, (Annual publications).
8 Fleiss JL. Statistical methods for rates and proportions. 2nd ed. New York: John Wiley, 1981:14-15.

9 James WH. What stabilises the sex ratio? Ann Hum Genet 1995;59:243-9.

10 Lam DA, Miron JA. Global patterns of seasonal variation in human fertility. Ann N Y Acad Sci 1994;709:9 28.

11 Russell D, Douglas AS, Allan TM. Changing seasonality of birth-a possible environmental effect. $\mathcal{F}$ Epidemiol Community Health 1993;47:362-7. 